\title{
Early Childhood Education in Botswana: A Case of Fragmented "Fits"
}

\author{
Langtone Maunganidze ${ }^{1} \&$ Marea Tsamaase $^{2}$ \\ ${ }^{1}$ Department of Sociology, University of Botswana, Gaborone, Botswana \\ ${ }^{2}$ Department of Family and Consumer Sciences, University of Botswana, Gaborone, Botswana \\ Correspondence: Langtone Maunganidze, Department of Sociology, University of Botswana, P Bag 00705 , \\ Gaborone, Botswana. Tel: 267-75-577-199. E-mail: langtone.maunganidze@mopipi.ub.bw
}

Received: August 20, $2013 \quad$ Accepted: October 30, $2013 \quad$ Online Published: April 22, 2014
doi:10.5539/ies.v7n5p1
URL: http://dx.doi.org/10.5539/ies.v7n5p1

\begin{abstract}
Scholarly and institutional research on early childhood education is not a new phenomenon, but what is perhaps limited is extant literature that particularly focuses on revisiting current practices and their "dialogue" with the ever-changing environment that prevails especially in an African setting. The practices of providers of early childhood education are either simply "business opportunity seeking" responses to the new consumption patterns of more affluent parent (or guardian) or current global trends of child education preparation. There has been a phenomenal increase in the number of early child centres in recent years but with fragmented structures. However whether or not this will reduce possibilities of tensions between the macro and micro aspects of this kind of co-evolution is one of the questions this article seeks to address. It also investigates the fit between the internal structure and processes of early childhood centers and the external environment (national framework), focusing on the challenges and prospects of early childhood education. Buoyed by the Fit/Congruence model of organizational analysis, the paper is based on findings from a content analysis of media reports and desk review of policy documents from purposively selected centres based in Gaborone. The data is analyzed using a combination of the pattern model and analytic comparison methods. In Botswana, one of the observed missing links is the absence of national framework guiding the structure and content of early childhood curriculum and instruction. It concludes that while the approaches used in these centres are relatively not similar they may be complementary particularly to the extent to which they prepare the children for an exclusionary education system in a country whose long-term vision is ironically to achieve an equitable and quality education for all. Institutional initiatives at national level have been limited and unevenly distributed with wide differences in the quality of services and lack of coherence and coordination at micro-level.
\end{abstract}

Keywords: early childhood, education, fit, congruence

\section{Introduction and Background}

Scholarly and institutional research on early childhood education is not a new phenomenon, but what is perhaps limited is extant literature that particularly focuses on revisiting current practices and their "dialogue" with the ever-changing environment that prevails especially in an African setting. One of the challenges confronting African education systems particularly in the early years is the attempt to achieve a congruence between what is happening within "school gates" and the real world albeit the imposing multiple environmental complexities and uncertainties or discontinuities. However whether or not this will reduce possibilities of tensions between the macro and micro aspects of this kind of co-evolution is one of the questions this article seeks to address The practices are either simply a "business opportunity seeking" response to the new consumption patterns of more affluent parent (or guardian) or deliberate strategies by policy makers in tandem with current global trends of child education preparation.

UNICEF Report (2008) defines early childhood development as relating to the physical, cognitive, language, social and emotional development of a child between the ages of 0 to 5 years. In Botswana the need for the provision of early childhood care and education is even more compelling for both child development practitioners and academics given the reported increase in early pregnancies, single parenthood and households exacerbated by HIV-AIDS and concomitant lack of appreciation and understanding of the children's early education needs. The first Early Childhood Education and Care (ECEC) facilities in Botswana were established 
shortly after the country's independence chiefly to serve the expatriate community (Bar-On, 2004; CfBT, 2008). Although the National Policy on Early Childhood Education was adopted in 1981, early child development has had a historical low priority in government budgeting compared to other countries in the region (see Table 1.). With the pre-primary and primary budget at $25 \%$ of education budget and the least in the group as at 2007, it is important to focus on this phenomenon. Although statistics are not always the best indicators, the picture presented may have direct implications for both the present analysis and possible future discussions.

Table 1. Pre-primary and primary education budget

\begin{tabular}{cccc}
\hline Country & $\begin{array}{c}\text { Education budget as } \\
\text { a \% of GDP }\end{array}$ & $\begin{array}{c}\text { Education budget as a \% } \\
\text { of Govt budget }\end{array}$ & $\begin{array}{c}\text { Pre-primary and primary education budget } \\
\text { as a \% of Education Budget }\end{array}$ \\
\hline South & 5.4 & 17.9 & 43 \\
Africa & 10.7 & 21.5 & 25 \\
Botswana & 6.9 & 21 & 60 \\
Namibia & 13.4 & 12.2 & 39 \\
Lesotho & 6.2 & 19.5 & 38 \\
Swaziland & 4.6 & $\mathrm{n} / \mathrm{a}$ & 30 \\
Zimbabwe & & & \\
\hline
\end{tabular}

Source: UNDP Human Development Report, 2007/8 (www.cfbt.com).

An attempt to address this gap was made with the recognition of early childhood education in several of the national and local policy documents (Revised National Policy for Education, 1994; ECCE, 2001) and the Botswana Vision 2016 which is understood as the premier strategic orientation of the nation (Vision 2016 Performance Report, 2009). The need to improve the quality of pre-school education facilities through closer monitoring and introduction of such programs in public primary schools is emphasized. This is also consistent with the UN Millennium Development Goals in which the first of the six goals set at the Dakar Forum on Education for All in 2000 proposed to "expand and improve comprehensive early childhood care and education, especially for the most vulnerable and disadvantaged" (Jaramillio \& Mingat, 2006, p. 2). Although pre-school education was considered a key component of integrated early childhood development programmes, it has the lowest participation rate among all levels of the broad education system in Botswana with only 17 percent attending some form of pre-primary school education (Botswana, 2007). In fact, the situation is partly aggravated by government's failure to partake or at least partly sponsor education at this level. ECCE programmes are only funded by government through the local authority (see Figure 1 below). In essence, preschool education in Botswana has always been and still remains a privilege to children of the elite as the required fees are immensely varied and exorbitant for an ordinary man (Bose, 2008). Recent studies by Bose $(2008,2010)$, observed an acute shortage of qualified and trained personnel particularly in public centers and this problem was exacerbated by the absence of a prescribed curriculum. However a lot of changes have occurred since then and the sector has witnessed phenomenal growth. For example according to the Gaborone Day Care Directory (2011) records, Gaborone alone had 81 registered early childhood care and education programs with ownership spread across different divides (see Figure 1 below). 


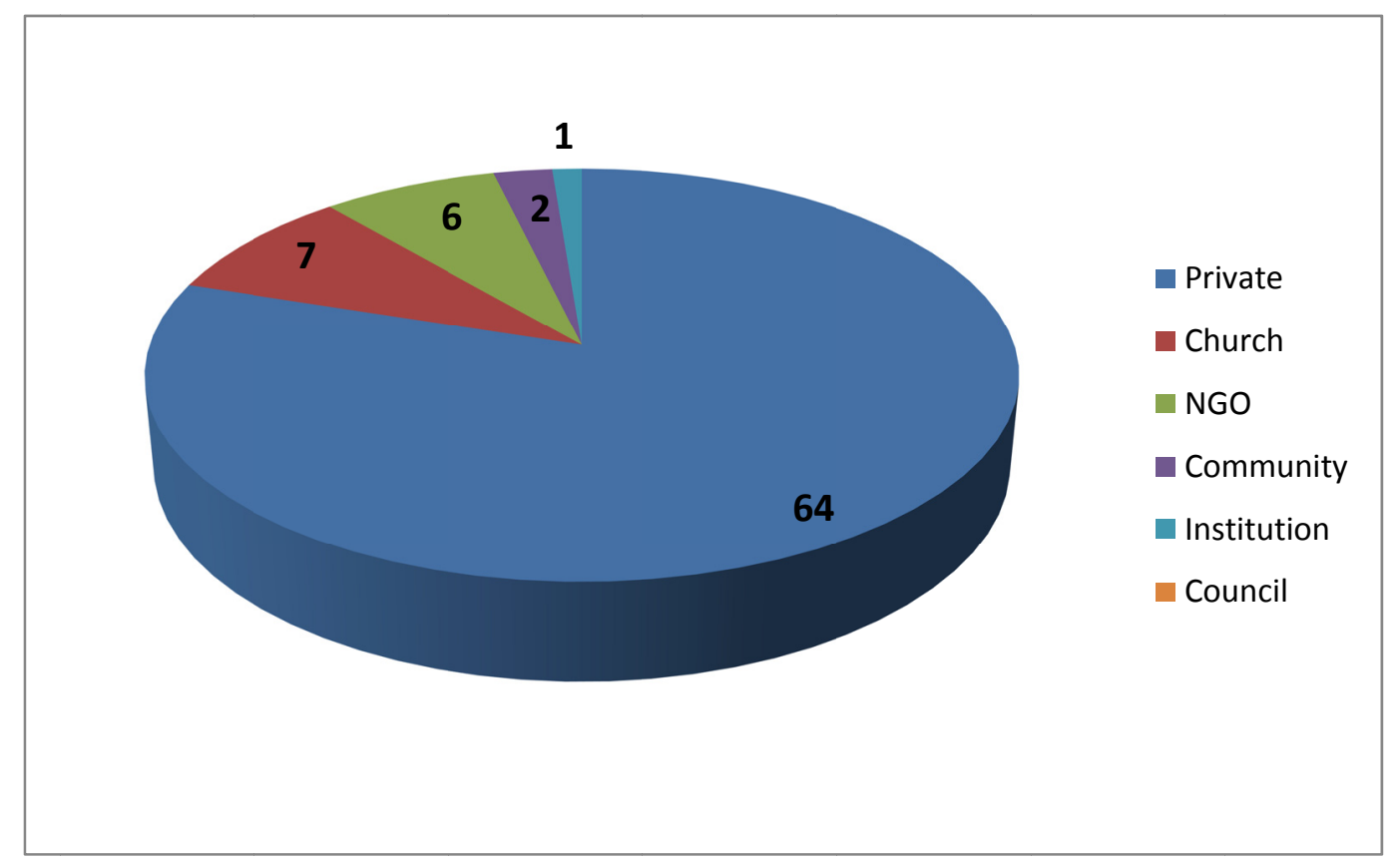

Figure 1. Types of centers by ownership (Source: Gaborone Day Care Directory (2011))

Ownership of early childhood care and education in Botswana is open to both locals and expatriates. There are basically no minimum requirements for owners as anyone can own an ECCE program without any relevant qualification so long as they employ personnel with the right qualification (ECCE, 2001). Also, as previously mentioned there is no standard curriculum nor set guidelines for monitoring teaching and learning at this level. Therefore, children's development and learning lies solely with each respective program. With the current relaxed policies on ownership of ECCE programs, ownership is predominated by expatriate individuals and groups arguably because they command sufficient financial capital needed for the successful establishment of such programs.

As earlier observed Botswana has a complex mix of types of early childhood care and education provision, conducted by a diverse range of providers operating in confusing and increasingly complex administrative environments. This shows how early childhood education programmes are unevenly distributed with fragmented and wide differences in both quantity and quality. While examples of best practice and quality care can be seen across program divide, education of young children at this level still remain a crazy-quilt, despite attempts to achieve a synthesis through policies at both national and local levels (Botswana, 1994, 2001). Other efforts to change the current status core specifically in teaching and learning of children at this stage have been made but have not been fruitful as yet. For instance, a curriculum for children from three to five years was developed and has been piloted since 2008 to date. Another positive step was taken by government in partnership with UNICEF to develop yet another curriculum for children from zero to three years in 2010. Both curriculums have not yet taken effect. Despite reputable attempts made which brought much hope to the field and practice, ECCE and its future in Botswana still remains a dream come true.

The existing differences in quality and outcomes within and between ECCE services offered in Botswana diverge from the growing body of international evidence showing effects of quality setting, experiences and pedagogy on children's wellbeing and developmental outcomes. Emerging from this evidence is the central role of early childhood practitioners in promoting quality experiences and environments for young children. Yet nationally, training for ECCE practitioners is still fragmented (Bose, 2008) and there is still no agreed position on how early childhood curriculum should be structured, or what values, learning experiences and outcomes could and should be expected and promoted.

This paper seeks to explore the nature and extent of early childhood education in Botswana. Although there is a recognition of the important role played parental education in early childhood development, the study only focuses on the formal systems not only because data is available and easy to analyze but to align it with internationally capable standards. It investigates the fit or congruence between the internal structure and processes of early childhood institutions and the external environment (national framework). It also examines the 
dimensions of fragmentation that tends to characterize the sector and their interface with child development and welfare. Although the analysis recognizes the symbiotic relationship between early childhood education and care or welfare, more focus is placed on education than care. The interdisciplinary nature of the field means that there will be a variety in every dimension of theories brought into the analysis. Premised on the Fit/Congruence model of organizational analysis, a qualitative case study approach is used. While content analysis of official and institutional documents and related literature on the issues is the dominant methodology used it is complemented by questionnaires and interviews that are administered to respondents (university staff, center educators and parents) selected by use of stratified random sampling design selected from institutions centres based in Gaborone. It is then analyzed using a combination of the pattern model and analytic comparison methods.

The paper is organized as follows: Firstly, it presents the introductory background to early childhood education in Botswana, followed by a conceptual and theoretical framework to the ensuing debates. Secondly, it examines the origins and dimensions of fragmentations and challenges confronting different actors. Finally, it concludes by demonstrating the effect of the imposing multiple environmental complexities and uncertainties or discontinuities within the sector on child development and suggest practical and policy related recommendations.

\section{Conceptualizing and Theorizing Fragmented "Fits" in the ECEC Sector}

The early child education sector comprising crèches, day-care centers, nursery schools, kindergarten, preschools and reception classes either privately or publicly owned make up the internal or micro-environment while Government institutional framework including formal primary education system, International partners such as UNICEF and other stakeholders not directly involved in the management of ECEC represent the macro-environment. According to the FIT Theory or Configuration logic (Burton et al., 2006, p. 13), "high organizational performance results from a strong external fit between the firm's overall strategy and its environment, and a tight internal fit among capabilities, structures, processes, and management philosophies". Misfit include deviation, misalignment, incongruence, out of kilter, incompatibility or gap (Burton \& Obel, 2004).

In Botswana, ECCE was characterized by a heightened degree of fragmentation and pluralism (Bose, 2008). For the ECEC providers, an analysis of external and internal fit suggests that both matter for performance and survival, however external misfit is more detrimental to performance than internal misfit. As a result of the current lack of strict and firm regulatory framework governing their operations in the form of lack of prescribed curriculum (Bose, 2010) and teaching and learning standards, the sector knows that this type of fit may just be a temporary state and would need to be proactive and collaborate as a sector to insulate itself against any changes likely to lead it into misfit. The current situation is what could best suit the sector but not necessarily the child. The diversity and plurality in ECEC terrain in Botswana resembles Dahlberg and Moss's (2005) proposition that misfits would occur when the centres are characterized more by the logic of commoditization and consumerism than ethic of care and child development. ECEC centers in Botswana include those that are by privately owned registered as commercial enterprises commonly located in urban and peri-urban or mining sites, educational institution-based such University of Botswana (predominantly for training purposes), those owned by NGOs and religious groupings, town councils or municipalities, and village development committees (Bar-On, 2004). Success or performance is measured differently depending on ownership and subsequently the motives behind the establishment. For example, the privately owned ones may be viewed as commercial enterprises while the village ones as feeding schemes and part of public works programme for employment creation. High performance for the sector occurs when early childhood education and care programs and activities are congruent to both national and internationally accepted practices. Both Fit and misfit are thus relative concepts.

\section{The Nexus between Fragmented Fits and Early Childhood Education}

The article advances the argument that attempts to achieve fit with environmental uncertainty or complexity can prevent or destroy internal complementarities (Miller, 1992; Nedopil, Steger, \& Amann, 2011). As Hannan and Freeman (1977) observed, "Internal pressures arise from internal structural arrangements and environmental constraints. Thus, we would not presume that a course of action that is adaptive for a single organization facing some changing environment will be adaptive for many competing organizations adopting a similar strategy"'(Garfamy, 2003, p. 12). The sector is characterized by fragmented structures and only those providers that manage to create the proper 'misfits' and then resolve them appropriately will be successful.

The effects of the lack of uniform regulatory and accountability frameworks on early childhood education are numerous and varied. The problem the ECEC sector is facing not only in Botswana but mostly in environments where there is weak or fragile regulatory framework is that of competition. In Botswana, the initial "hands-off approach" (Bar-On, 2004), which tended to leave everything to the market forces exposed the child to 
inappropriate preparation. The centers depending on the owner's orientation also served different functions. While some provided custodial care to young children others functioned as "pre-schools" or preparatory classes for the primary school level. For example, some centers which are registered as commercial enterprises and owned by expatriates are beyond the reach of most locals. Their curriculum is also predominantly attached to English medium schools and slanted towards an exclusionary and elitist system which does not resonate well with the country's vision of a universal and equitable access to quality education for all Batswana. For those that are owned by citizens, the motive is often purely entrepreneurial. As a result of the entrepreneurial development funding being provided by Citizen Entrepreneurial Development Agency (CEDA) and Local Enterprise Authority (LEA) (both institutions are supported by the Botswana government), recently there has been a mushrooming of "Day Care Centres" in cities particularly Gaborone. For most female entrepreneurs this is a lucrative business opportunity given the urbanization and rising affluence of Batswana particularly young working mothers who would require only day custody of their children (www.cfbt.com; Bar-On, 2004). The problem is that most pre-schools are not understood as public good and sites of ethical practice but rather as enterprises producing tradable commodities (Dahlberg \& Moss, 2005; Robinson \& Diaz, 2006).

Apart from the danger of possibly operating illegally and with no regard for "rights based" education and care values (Penn, 2008), the fragmentation may result in heterogeneous curricula that will not necessarily be suitable for formal education and school readiness. Without a prescribed curriculum for this level and any links with primary schools which received their graduates these centers complete the list of the 'fragmentations' experienced in the sector. Cognitive development of children less than 5 years is compromised by low and uneven delivery of early childhood education (ECE) (UNICEF, 2011, p. 9). Children exposed to early childhood education, particularly formal pre-schools are more prepared and more likely to remain in school (UNICEF and UNESCO, 2011). Evidence from our interviews support previous findings that children who have not been exposed to pre-school education programmes would take long to adapt to the primary education curriculum. However the challenge Botswana faces is that while there are progressive developments in reforming the basic education sector in line with international and regional trends there is very little of that nature occurring at ECEC levels.

\section{Challenges and Prospects for Congruence}

The prospects and possibilities for a fit or congruence in this sector though not far-fetched will not be easily attained. The interests of actors particularly owners or shareholders of these centers and those of public through government and international institutions such as UNICEF are at variance. There is an interaction of two different systems with no visible and structured boundaries. The practices are either simply a "business opportunity seeking" response to the new consumption patterns of more affluent parent (or guardian) or deliberate strategies by policy makers tangent to current global trends of child education preparation. As already observed in this paper, some owners view ECEC centres as business enterprises producing "tradable commodities" while others are of the view that they are "public" institutions. Since all ECEC centers like any other organizations, are value laden and ideological, they will always configure their goals, boundaries and activities in response to the changing environment. The belief in the existence of organizations as concrete, stable and identifiable free-standing entities with distinctive boundaries obscures and distorts our understanding of reality (Chia, 1996; Hassard \& Parker, 1993).

Institutional initiatives at national level have been limited and unevenly distributed with wide differences in the quality of services and lack of coherence and coordination. For example, according to the UNICEF 2010/11 Situational Report on Botswana, the Education Act does not recognize the child right to early education and this right is only enshrined in the Children's Act (2009) which calls for district wide provision of ECE (Early childhood education). This inconsistency and lack of standardization or institutional harmonization have severe implications for the provision of early education and even the entire lifespan of the child. All these programmes were supposed to be assessed against the standard that they "consist of organized and sustained school-based or centre-based activities designed to foster learning and the emotional and social development of children" (EFA 2000; Assessment Technical Guidelines, 1998, p. 8). Only a few of the service providers, mainly the kind that are organized in primary schools as pre-school or reception classes, will meet that standard. The majority of other service providers include local NGOs who depend on donor funding, playgroups or babysitting services, and more importantly, care providers that are based in their homes. These may not be up to the standard that is required under the EFA Guidelines.

The issue of prescribed curriculum earlier on mentioned in the paper needs some kind of deconstruction. Furthermore, whether or not this will reduce possibilities of tensions between the macro and micro aspects of this sector is one of the critical questions for discussion. How does a prescribed curriculum resolve the 
fragmentation that exists in terms of different visions and cultures, structural discontinuities and crisis of expectations among various interest groups? The paper advances an argument already observed in previous researches (Penn, 2000; Fabian \& Dunlop, 2002; Anning et al., 2004) that there is no consensus on what the best curriculum should constitute. The nature of knowledge embedded in curriculum models and their implementation is mediated by adult ideologies, beliefs or political imperatives. Curricula are socially constructed and always reflect the dominant values of the system they serve and appropriate curricula for early childhood education should be premised on the concept of co-construction of knowledge by all actors. One more challenge confronting the possibility of creating a better fit in the sector is the pedagogical discontinuity existing between the ECEC centres and primary school system which will finally absorb the "graduates". These two systems do not seem to know each other well. As have been observed some centers such as village ones are perceived as feeding scheme points while the privately owned exclusive urban based are expected to transmit early childhood skills and knowledge that prepare children for the English medium school. The degree of diversity and pluralities within the sector renders efforts at creating a common ground for strong and equal partnership relatively futile.

\section{Conclusions}

This article concludes that there is no consensus on the purposes, structures, processes and methods of running of the ECE sector in Botswana. The findings support earlier observations (Bose, 2010) that one of the missing links is the absence of national framework guiding the structure and content of early childhood curriculum and instruction. There has been a phenomenal increase in the number of early child centres but with fragmented structures. Early childhood education programmes in Botswana are not only as varied as they are providers but unevenly distributed with fragmented and wide differences in quality. The terrain in ECEC sector is not only diverse and different but fragmentary and contested. This makes attempts at creating a comprehensive institutional national framework a partial success.

While the approaches used in these centres are relatively not similar they may be complementary to the extent to which they prepare the children for an exclusionary education system in a country whose long-term vision is to achieve an equitable and quality education for all. This study confirms earlier observations made elsewhere (Robinson \& Diaz, 2006) that ECEC institutions constitute and perpetuate many of the discourses that underpin social inequalities through education programmes.

\section{Recommendations}

The paper recommends the need for "community-based" approaches through the active participation of all stakeholders and informed by a centrally coordinated institutional policy framework to ensure sustainable childhood development and preparation practices. The empowerment of children, parents and families that arises from a partnership approach can lead to sustainable benefits to early childhood development (Hadeed, 2005). This should be supported by a national framework on monitoring curriculum and instruction of early childhood education. This would facilitate congruence by ensuring that the diversity that characterizes the sector is not a source of conflict but fundamentally complementary.

There is an urgent need to benchmark the current performance with internationally accepted practices within the continent in general and Southern Africa in particular. In order to possibly "expand and improve comprehensive early childhood care and education especially for the most vulnerable and disadvantaged"; the programs should be made compulsory and school-based for easy monitoring. The government should play a more visible role through direct involvement by treating ECE as a "public good" to ensure unconditional access.

There should be communication between ECEC educators and the formal primary school in order to deal with different perceptions and expectations. Effort should be directed towards facilitating both structural and pedagogical integration.

\section{References}

Anning, A., Cullen, J., \& Fleer, M. (Eds.). (2004). Early Childhood Education: Society and Culture. London: Sage Publications.

Bar-On, A. (2004). Early Childhood and Education in Africa: The Case of Botswana. Journal of Early Childhood Research, 2(1), 67-84.

Bose, K. (2010). The Issue of Holistic Development of Young Children in ECE Centers in Botswana. Literacy Information and Computer Education Journal (LICEJ), 1(2), 433-449.

Bose, K. (2008). Gaps and Remedies of Early Childhood Care and Education. Education and Review, 3(3), 
$77-82$.

Botswana. (2007). A needs Assessment and Costing Exercise for Achieving the Millennium Development Goals in Botswana. In Vision 2016 Botswana Performance Report, 2009.

Burton, R. M., \& Obel, B. (2004). Strategic Organization Diagnosis and Design: The Dynamics of Fit. Boston: Kluwer Academic Publishers.

Burton, R., Ericksen, B., Hakonsson, D., \& Snow, C. (2006). Organization Design: The Evoloving State-of-Art. New York: Springer.

Dahlberg, G., \& Moss, P. (2005). Ethics and Politics in Early Childhood Education. Oxfordshire: RoutledgeFalmer.

Fabian, H., \& Dunlop, A.-W. (2002). Transitions in the Early Years: Debating Continuity and Progression for Young Children in Early education. New York: Open University Press.

Gaborone Day Care Directory. (2011). Gaborone.

Garfamy, M. R. (2003). Organization Theory as a Scientific Research Program. Autonomous University of Barcelona: Barcelona.

Hadeed, J. (2005). Poverty Begins at Home: Mother-Child Education Programme in the Kingdom of Behrain. New York: Peterlang.

Hassard, J., \& Parker, M. (1993). Postmodernism and Organizations. London: Sage Publ. Ltd.

Jaramillio, A., \& Mingat, A. (2006). Early Childhood Care and Education in Sub-Saharan Africa: What would it take to meet the millennium development goals? Association for Developmernt of Education in Africa (ADEA), Biennale on Education in Africa. Libreville, Gabon, March 27-31, 2006.

Miller, D. (1992). Internal fit vs. external fit. Organization Science, 3(2), 159.

Nedopil, C., Steger, U., \& Amann, W. (2011). Managing Complexity in Organizations. Text and Cases. London: Palgrave Macmillan.

Penn, H. (2000). Early Childhood Services Theory, Policy and Practice. Buckingham: Open University Press.

Penn, H. (2008). Early Childhood Education and Care in Southern Africa: A Perspective Report. University of East London: CfBT Education Trust.

Robinson, K. H., \& Diaz, C. J. (2006). Diversity and Difference in Early Childhood Education: Issues for Theory and Practice. New York: Open University Press.

UNICEF. (2008). Social Protection in East and Southern Africa: A Framework and Strategy for UNICEF. Nairobi: UNICEF East and Southern Africa Regional Office.

UNICEF. (2011). The Situation Analysis of Children and their Families in Botswana: Summary Report. Findings and Recommendations to Policy makers. Gaborone: UNICEF, Botswana Country Office.

UNICEF/UNESCO. (2011). Global Initiative on Out of School Children; Conceptual and Methodological Framework. New York. UN.

\section{Copyrights}

Copyright for this article is retained by the author(s), with first publication rights granted to the journal.

This is an open-access article distributed under the terms and conditions of the Creative Commons Attribution license (http://creativecommons.org/licenses/by/3.0/). 